\title{
DESCRIPTION OF THE PREPARATORY STAGES OF CALLOSAMIA PROMETHEA DRURY.
}

\author{
BY WM. BEUTENMULLER, NEW YORK.
}

Egg.-Oval, slightly flattened above and below, sordid white. Height $1.20 \mathrm{~mm}$. Width r.50 mm. Laid June 14. Emerged June 24.

Larva: First stage. - Head dull black with a sordid white transverse band across the middle. Body greenish yellow with a transverse black band on the anterior and posterior portions of each segment, running to the sides.

Along the dorsum are two rows of tubercles, and a row along the subdorsal and another row along the sides below the spiracles. All the tubercles are yellow, except those on the first segment and the two dorsal pairs on the second and third segments and those on eleventh and twelfth segments, black. Each of the tubercles are also furnished with about five bristle-like hairs, which are black. Length $3 \mathrm{~mm}$. Duration of this stage seven days.

After first moult. - No change except that the larvae are more conspicuous. In some individuals of the brood the two tubercles on dorsal region on the second and third segments are yellow instead of black as in the previous moult. Length Io $\mathrm{mm}$. Duration of this stage five days.

After second moult. - The body is now whitish green, with the tubercles black, except the two dorsal pair on the second and third segments and the one on the eleventh segment bright yellow, with their bases black; these six tubercles remain present in all the subsequent stages, while all the remaining tubercles gradually become reduced into mere piliferous spots. Anal plates yellow margined with black. Head yellow, with a black transverse band and a black spot on each side of the top. All the feet yellow, abdominal ones with a black spot on the outer side of each. The transverse bands across the segments are now quite faint, and in some specimens they are broken or absent. Length $20 \mathrm{~mm}$. Duration of this stage four days.

After third moult. - The body color is the same as in the previous moult. The four tubercles on the second and third segments are now bright orange yellow and the one on top of the eleventh segment lemon yellow; all other tubercles black and much smaller than the ones just mentioned. Thoracic feet and anal legs yellow, abdominal legs same as in the last stage. Head yellow with two black spots on each side. Length $24 \mathrm{~mm}$. Duration of this stage three days.

After fourth moult.-Body entirely green, with a whitish hue. The transverse bands have now disappeared. The four tubercles on the second and third segments are now quite prominent, coral red, and the one on the eleventh segment lemon yellow. All the other tubercles are reduced to mere piliferous spots. Head and legs yellowish green. Length $30 \mathrm{~mm}$. Duration of this stage five days.

After fifth or last moult.-Same in all respects as the preceding moult, except that the larva becomes stouter and more prominent in appearance. Length $39 \mathrm{~mm}$. The full grown larva measures about $55 \mathrm{~mm}$. Duration of this stage five days.

Food-plants.-Sassafras, tulip-tree, linden, spicebush, sweet-gum, choke-cherry, plum, pear, ash, Magnolia, Halesia, etc.

The early stages of this species were made first known by Dr. C. V. Riley, (4th Mo. rep. p. I2I) who gives only four moults, while the brood I raised moulted five times. The mature larva was first figured by Abbot and Smith (Ins. Ga., v. I, p. 9I, pl. 46) and again subsequently by various writers. 

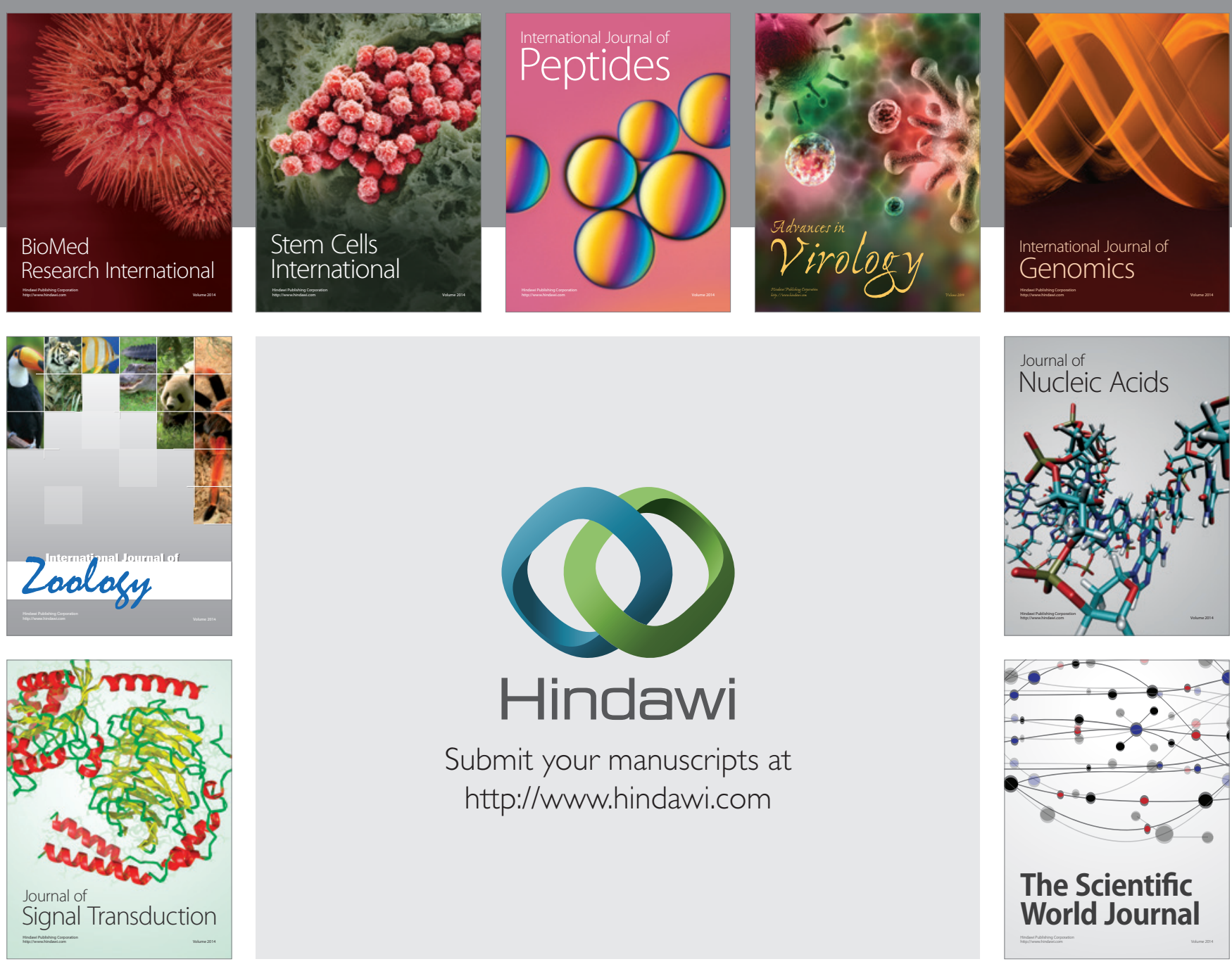

Submit your manuscripts at

http://www.hindawi.com
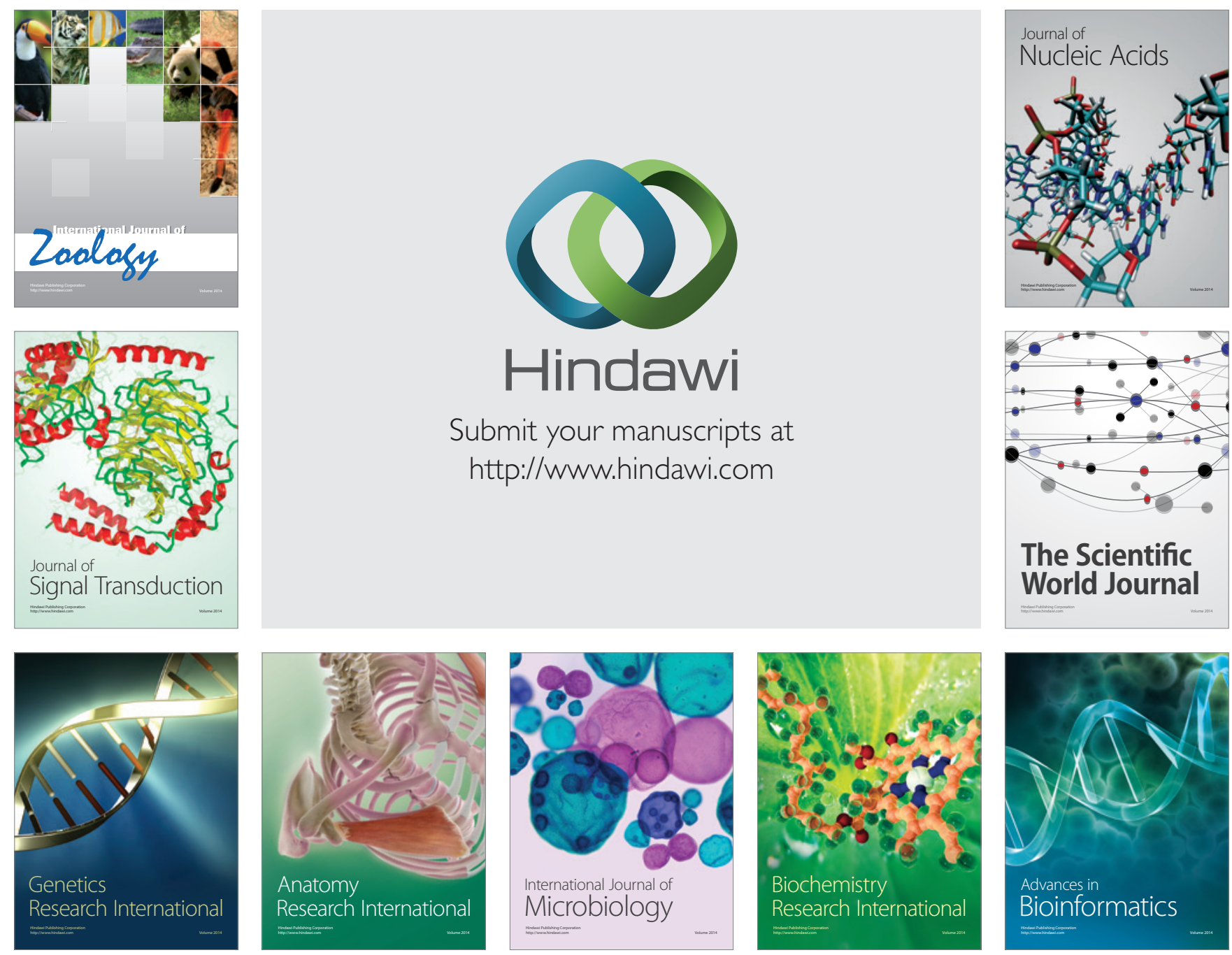

The Scientific World Journal
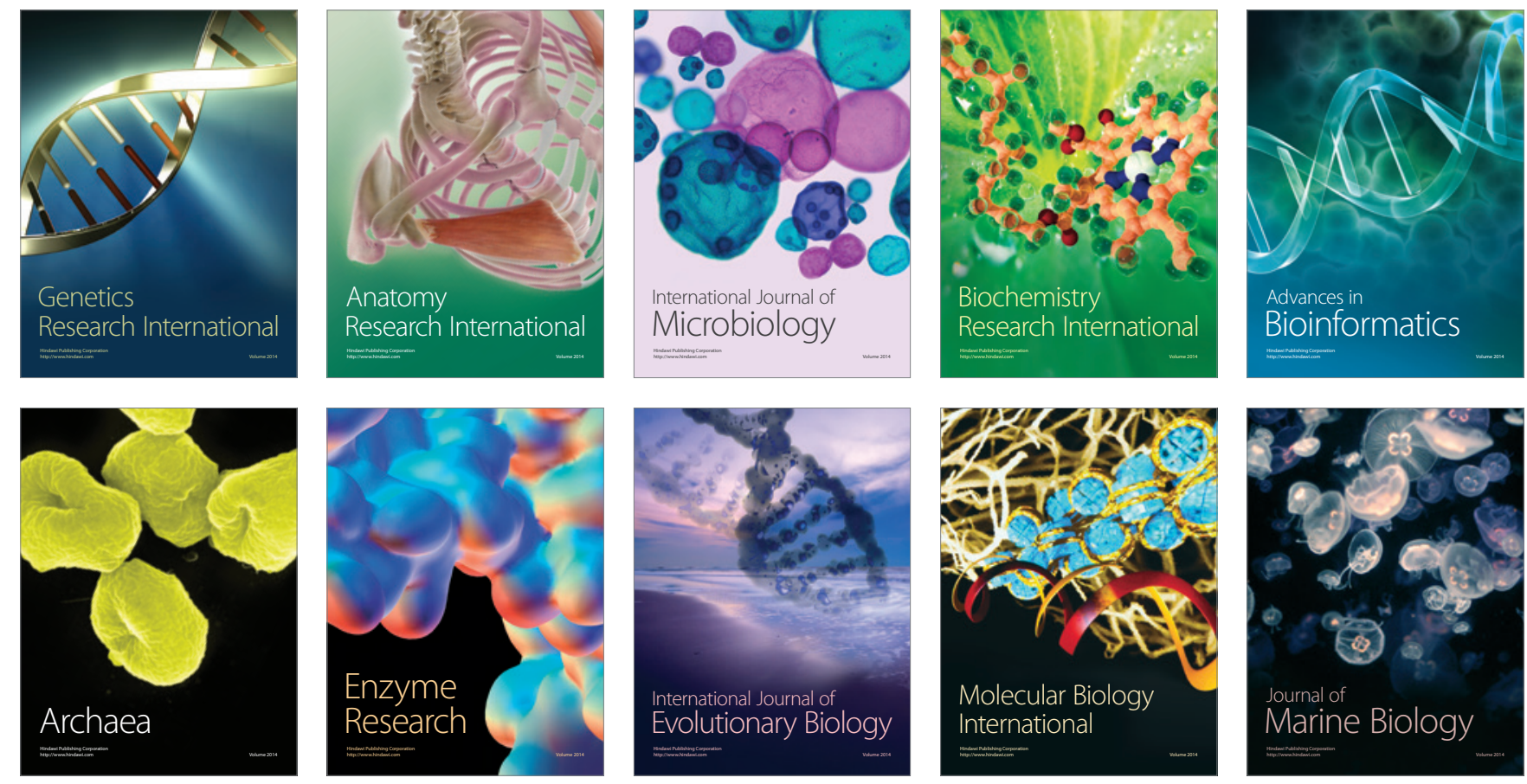